Foro Interno. Anuario de Teoría Política

ISSN: $1578-4576$

http://dx.doi.org/10.5209/FOIN.61513

\title{
Barbara Arneil, Domestic Colonies. The Turn Inward to Colony, Oxford University Press, Oxford, 2017. 287 páginas. ISBN: 978-0-19-880342-3.
}

Entender el colonialismo como una cacofonía de luchas horizontales y hegemónicas ofrece una forma alternativa de formular y abordar dinámicas en las que se continúa afectando tanto a las personas que se desplazaron como a las que fueron forzadas a desplazarse dentro del imperio (p. 247) ${ }^{1}$.

El estudio de la profesora Barbara Arneil ${ }^{2}$ parte de la intención por lograr una corrección teórica en la concepción general tanto de los espacios poscoloniales como del colonizado (p. 248). Manteniendo un contraste con la visión sobre la dominación propuesta por Michel Foucault (1926-1984), que señala el ejercicio de un poder "desde adentro del subyugado", la propuesta de la autora inicia con un análisis histórico que involucra la presencia de tres variables que permanecen: segregación, trabajo agrario y mejoramiento del individuo (p. 178). Es la presencia misma de dichas variables lo que ocasiona un desacuerdo con la mirada propuesta por Foucault; es decir, una contraposición a los conceptos de vigilancia, dominación y control (p. 169). La discordia de la que se origina este análisis parte desde los orígenes linguísticos de "colonia" como palabra $^{3}$ (p. 23) y abarca hasta la forma práctica en que han funcionado la colonia como unidad histórica, el colonialismo como ideología y la colonización como proceso ( $\mathrm{p}$. $3)$. En los siglos diecinueve y veinte las intersecciones coloniales de la modernidad dieron forma visible a un aspecto poco estudiado: la colonización doméstica (p. 36).

Uno de los puntos ciegos en los estudios poscoloniales es — argumenta la auto$\mathrm{ra}$ - la tendencia a asociar imperialismo y colonialismo resultando indistinguibles ( $\mathrm{p}$. 17). Analizar este fallo nos llevaría por necesidad a mirar hacia el pensamiento de John Locke (1632-1704) como una forma embrionaria del pensamiento colonial y a considerar su defensa de la colonización en América para enfatizar la importancia de los beneficios económicos y éticos de la colonización (p. 25). Arneil sostiene que considerar la importancia central de los beneficios éticos sobre el "mejoramiento del individuo" y la influencia del trabajo agrario es lo que nos haría salir del equívoco sobre

"[U]nderstanding colonialism as a cacophony of contradictorily hegemonic and horizontal struggles offers an alternative way of formulating and addressing dynamics that continue to affect peoples as they move and are made to move within empire". La cita es del profesor de estudios indígenas Jodi Byrd.

2 Barbara Arneil es profesora de Teoría Política en el Departamento de Ciencia Política en la Universidad de Columbia Británica (Canadá). Está especializada en la intersección entre el liberalismo y el colonialismo. Aunque sus trabajos más recientes abarcan áreas como la confianza social, la diversidad, la ciudadanía global, el cosmopolitismo, así como el papel de la discapacidad en la teoría política. De hecho uno de sus últimos trabajos publicados ha sido la coedición del libro Disability and Political Theory (Cambridge University Press, 2016). En su trayectoria ha sido reconocida con multitud de premios, algunos de los más recientes en 2018: el Premio C.B. McPherson de la Asociación Canadiense de Ciencia Política y el Premio David Easton de la Asociación Americana de Ciencia Política.

3 Colonia, cuya raíz está ligada etimológicamente a colere: cultivo de la tierra; y a colonus: agricultor (p. 23). 
la dicotomía castigo-dominación (p. 36) para así realizar un análisis histórico sobre los diferentes tipos de colonias enmarcadas hasta la primera mitad del siglo veinte. Es importante señalar que el contexto en el que se propagaron y desarrollaron tanto la idea del mejoramiento del individuo, subrayada por la autora, como los beneficios éticos de la colonización, es la llamada era del imperio ${ }^{4}$, el siglo diecinueve tardío y comienzos del siglo veinte; época en la que también el imperio colonial ${ }^{5}$ se desenvolvió. Es en este contexto en el que ciertos políticos y pensadores defendían la colonización doméstica, argumentando que los mismos fines se podían lograr más fácilmente y con menos costos vía "home colonies" en lugar de mediante colonias en ultramar (p. 53).

Muestra la autora que aunque el proceso de colonización comenzó practicándose hacia afuera, vía colonización externa, este tuvo un viraje hacia adentro (p. 223) ya que los beneficios sociales y de ahorro económico resultaron consideraciones importantes ante los crecientes problemas de desempleo y crimen. Esta nueva práctica se contrapondría al envío de criminales y desempleados a colonias externas, gracias al cual se había implementado en un primer momento la creación de colonias de trabajo (p. 51). El proceso de colonización en su conjunto, es decir, interno y externo, debe ser entendido entonces desde un análisis doble: en materia de política interna de los Estados; y en las perspectivas hacia su política exterior (p. 73). Internamente se buscaba mejorar a criminales y a desempleados para que se convirtiesen en productivos trabajadores industriales (p. 43).

En este punto sería válido preguntar si la formación de entidades imperiales y/o coloniales que abarcan un mismo periodo de tiempo, en una geografía análoga y con estrategias de: a) dominación, b) desplazamiento y c) despojo similares, son radicalmente diferentes y si estas contrastan con las ideas de Locke sobre la segregación, el trabajo agrario y el mejoramiento del individuo (p. 29). Realizar esta pregunta es también cuestionar la tesis central del trabajo aquí reseñado. Para explicarlo de una manera más clara, la autora establece que la formación de espacios coloniales no puede ser entendida como una colonización externa solamente; por otro lado, propone analizar la formación colonial también como un espacio doméstico e intrínseco de los Estados analizando la historia de los lugares que fueron llamados explícitamente colonias. Este hecho - realizar un análisis desde esta perspectiva - nos lleva al título del libro y a realizar un giro hacia adentro de la colonia (p. 248). El giro hacia adentro consiste en analizar los espacios coloniales, específicamente de colonización doméstica, y estudiar las distintas y múltiples narrativas, llamadas intersecciones coloniales (p. 245), que los conforman, para comprender que no necesariamente todas las lecturas deben partir de una relación de dominación y vigilancia (p. 160).

El desacuerdo con Foucault y con los historiadores sociales especializados en eugenesia aclara que existen distintas y múltiples narrativas en la creación de colonias domésticas (p. 171). Esta apertura en la concepción de las colonias internas nos permite entender que estas formaciones son más complejas. No pueden simplificarse como un método de segregación para evitar la reproducción, ni tampoco quedar reducidas a un poder disciplinario de sometimiento y control hacia el oprimido (p. 178). Para mostrar estas complejidades la autora realiza un estudio que comprende desde la creación de la primera colonia doméstica, en la que se buscaba castigar y

Eric Hobsbawm, La era del imperio, 1875-1914, Editorial Planeta, México, 2015, p. 65.

Ibid., p. 66. 
convertir al desempleado ${ }^{6}$, hasta la utilización de las colonias como un modelo de emancipación social para el pueblo afroamericano en los Estados Unidos de América (p. 217). La historia de la colonización, incorporando esta mirada, muestra que el modelo de colonias domésticas fue exportado desde Europa, especialmente por Holanda, Francia y Gran Bretaña (p. 71), hasta América del Norte - los actuales territorios de Canadá y Estados Unidos (p. 108)-. Allí atravesó distintas formas de gobierno y sufrió cambios en cuanto a sus objetivos y su funcionamiento dependiendo del contexto nacional e ideológico en el que fuera instalado.

Tanto teóricos defensores del capitalismo liberal como del pensamiento anarquista — véase el caso de Piotr Kropotkin (1842-1921) — integraron la creación de diversas colonias domésticas y se sirvieron de diferentes mecanismos para fines múltiples (p. 199). Es importante mencionar que el estudio hacia adentro de la colonia muestra las contradicciones en las que puede caer la historia del pensamiento colonial; muestra que tanto Thomas Jefferson (1743-1826) como Abraham Lincoln (1809-1865) (p. 88) fueron partícipes de la colonización, y desafía la visión generalizada de su idolatría en favor de los derechos políticos y civiles. Por otro lado, Arneil nos hace ver que el pensamiento socialista desarrollado en Gran Bretaña y Estados Unidos por Robert Owen (1771-1858) se puede mostrar desencantado si se desvela que para la implementación de las colonias utópicas se utilizó una estrategia de despojo hacia los pueblos originarios que ahí habitaban (p. 199). Así mismo, en Prusia, el nacionalismo de la época defendido por Max Weber (1864-1920) llevó tanto a una auto-colonización, similar a la que Rusia ha realizado a lo largo de su historia, como a un despojo de las poblaciones polacas que habitaban en la zona este (p. 68).

En definitiva, segregación, trabajo agrario y mejoramiento del individuo son las tres variables que acompañan el análisis de las colonias domésticas. Aun así, considero importante observar que todas las colonias aquí analizadas corresponden de igual manera a una relación de poder, razón por la cual desechar el argumento de Foucault puede sesgar nuestra comprensión sobre los modelos coloniales. Sin importar si las colonias fueron creadas por organizaciones privadas o por una estructura estatal, estas son constituidas desde la imposición de una estructura externa hacia el conjunto social colonizado.

La importancia de las colonias domésticas nos hace reflexionar sobre casos que no pueden ser analizados a través de otra lógica, y a concluir que incluso las colonias utópicas ejercieron un poder sobre otro constructo social. El trabajo de Arneil es, por todo ello, esclarecedor y contribuye al debate teórico necesario para la incorporación de aspectos olvidados en los estudios coloniales y poscoloniales. La redefinición de conceptos y la transversalidad de la colonización desde esta mirada ayuda a lograr una comprensión más completa sobre la imagen dinámica y cambiante de los espacios coloniales. Nos dirije a saber que la cacofonía de luchas horizontales y hegemónicas puede ser vislumbrada no solamente en un entendimiento de dominación imperial sino que debe serlo a través de la multiplicidad de narrativas existentes que conforman el giro hacia adentro de la colonia.

\author{
Mario Isaac Menes Espinosa \\ University of Miskolc (Hungría) \\ menesmario.ei@gmail.com
}

"[U]no de los mayores pecados políticos y económicos era estar desempleado y ser pobre" [... one of the greatest political and economic sins of the modern era was to be idle and poor] (p. 37). 